\title{
Interactive tangible planning support systems and politics of public participation
}

\begin{abstract}
The complexity of the contemporary city stems from the numerous positions of its interpretation. The two most relevant to this paper are the augmentations of cities through digital technology and the ever-more-present participation requirement in the urban planning process. On one hand, digital technologies are promising efficient running of cities and better decision-making through a larger volume and better detail of information. On the other hand, the participatory agenda suggests a more levelled playing field for different stakeholders and a wider consensus. Both positions have limits - the first in the myriad of data produced that makes the digital city unreadable to the public and decision-makers without the help of specialized professionals, and the second in forming and keeping a consensus between stakeholders in the planning process. This paper explores how these limits can be addressed. Recently, interactive tangible planning support systems (PSSs) have been promoted to improve the established urban planning and participation methodologies. They promise to make digital spatial data more accessible in the decision-making process and to establish a better consensus amongst stakeholders. This paper will compare two examples of the interactive tangible PSSs in order to illuminate how the interactive environments increase the usability of professional spatial information on one hand and how they contribute toward consensus-making on the other.
\end{abstract}

Keywords: interactive tangible planning support systems, public participation, planning process, politics

\section{Introduction}

Contemporary cities are becoming ever more complex and increasingly difficult to manage. This is creating a multifaceted urban environment that is claimed by an ever-larger number of diverse stakeholders. Developers, multinational firms, entrepreneurs, investors, economic experts, the local public, engineers, architects, artists, etc.: all these different groups are claiming the right to define, organize and voice their opinions about what, how and in what way their cities should be shaped. Their claims are more often than not in stark contradiction; for example, the wishes and demands of the local public are usually diametrically opposed to the wishes and demands of the developers.

Latour (2004) refers to this problem as "the matters of concern", where every claim can be contested and should be part of an open discussion in which all constituencies, human and nonhuman, have a voice and an equal right of representation. In other words, reality in contemporary culture has different manifestations-from scientific, economic and technical descriptions of material processes with an emphasis on efficiency; to political and moral concerns for sustainability; to sentimental attachments to places, animals, and holidays. The fast-changing, fragmented reality of late capitalism promotes multiple interpretations, all apparently of equal value. Therefore, matters of scientific fact and matters of personal concern create a field of truths, each from a specific point of view and with a specific agenda. There are no more "risk-free objects" that exist free of judgment (Latour, 2004: 25). 
Within this framework, the present paper will discuss two topics: first, the digitization of urban governance and planning through the arrival of information technologies into the city debate and, second, the plurality of contemporary planning processes and the way consensus is being shaped by information technology.

\subsection{Information technologies and urban governance}

The problem of use of information technologies (IT) in urban planning and management can be explained by examples of intrusion of companies such as Siemens or IBM, which has created a new city market, connected to urban governance and planning. One of the more significant changes indicating this shift can be traced to technology fairs such as the CeBit in Hanover, Germany. Ten years ago, the fair was mainly focused on consumer electronics boasting new processors and digital gadgets; nowadays however, IBM and other technological giants are mainly focusing on the "soft part" of digital production, such as Software as a Service (SaaS) solutions for the city market. One such example is IBM's SaaS called "Intelligent Operations Center" (IOC) (Internet 1). Rio de Janeiro is using the IOC platform to create the operations centre for the Prefecture of Rio, bringing all of its utility services under one roof (Figure 1). According to IBM, IOC technologies and services such as "integrated data visualization, realtime collaboration, and deep analytics help city agencies prepare for problems, plan for growth, and coordinate and manage response efforts" (Internet 1).

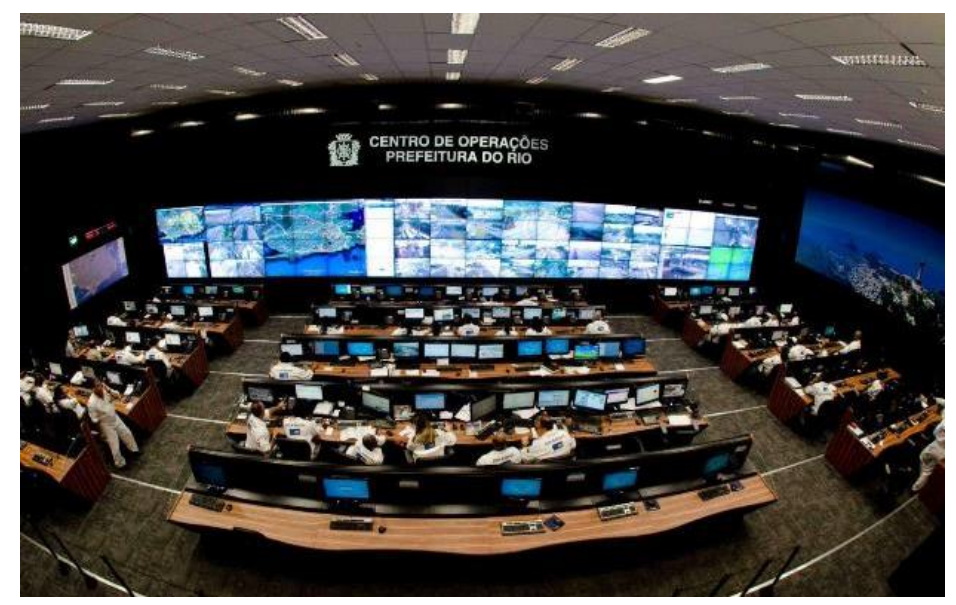

Figure 1: IBM Intelligent Operations Center: an IBM solution for the Prefecture of Rio bringing all utility services under one roof (source: Internet 2).

This development is commonly presented as the "smart city" trend in contemporary urban planning and governance. In recent popular discourse, the word "smartness" has been used to describe a cybernetic system through which nature and culture are converted into digital information, and managed as such. The tendency to approach urban and cultural phenomena by raising them to ever more abstract levels of conceptualization makes their management appear easier (and more profitable for IBM), but it is achieved at the cost of reducing cultural and ethical issues to a managed system of figures, depriving them of all substantial content. Due to the need for economic efficiency and the persistent lobbying of the digital technology giants in the urban development sector, cities incorporate the digital solutions in order to stay current (Pipan, 2014: 158). In addition, this practice is perpetuated for political reasons to demonstrate to citizens and the public that the city administration is capable of proficient city management by increasing the wellbeing of individuals - the most important value indicator of a successful city. 
The term smart city is heavily contested within the academic literature, from urban geographical definitions linking it to the knowledge economy (Caragliu et al., 2011) to humanities definitions referring to its ethics and meaning (Kitchin, 2016). However, a review of city literature shows a distinctive rise of the smart city debate from 2009 onwards as the field around smart city topics "constitutes a new collection of keywords and related concepts" (de Jong et al., 2015: 34). As there might never emerge a single smart city definition, we will be using the broader philosophical idea of Bunschoten (2018:774), who states that the "essence of the Smart City is the ability to control interactions between a user, a system, and the environment". To this we might add that the purpose of such control is economic gains, something that IT multinationals like IBM, Google, and Siemens have achieved by establishing a new city market. The digital giants are additionally supported by large engineering firms since the smart city offers "concrete innovation and investment opportunities for physical urban and infrastructure development" (de Jong et al., 2015: 34).

Within this heavily contested environment, saturated with information, the geographic information system (GIS) has been a classical solution leading the standard approach of spatial management, analysis, and planning. With new solutions and an ever increasing amount of data, it is becoming necessary for municipalities to "foster GIS specialists who can select GIS software and hardware suitable for individual local government, prepare appropriate spatial data, and master them" (Kohsaka, 2000: 279) and that "experts and individuals who are comfortable with GIS and spatial reasoning are focused to a greater extent on data creation and visualization using technology rather than decision-making processes" (Kar et al., 2016: 297). This leads us to the conclusion that in the contemporary information-saturated age, data cannot be accessed or viewed without an expert-technician, which consequently makes the process of decision-making slower. It is worth noting that the decision-makers and GIS professionals are two separate occupations. As Campagna and Deplano conclude, "GISs are farther away from being used in planning than one would expect and [the reason that] GISs are persistently underutilized [...] might be that GIS packages never satisfy the planner's need for flexibility" (Campagna \& Deplano, 2004: 23). Attempts to address this problem have given rise to a new direction in digital tools called planning support systems (PSSs). PSSs "bring together the functionalities of geographical information systems (GIS), models, and visualization, to gather, structure, analyse, and communicate information in planning" (Vonk et al., 2007: 1699). These promise to help make the utilization of spatial data simpler and more accessible to nonprofessionals such as decision-makers and public participants. The interactive tangible PPSs presented in this paper focus on the visualization and communication segment, as their main goal is to make access to professional GIS information easier for non-professionals.

\subsection{Information technologies and public participation}

To outline the background of the second problem related to public participation we have to consider the question of the plurality of contemporary politics. Latour (2004) talks about a shift from "matters of fact" to "matters of concern" as a consequence of the post-modern condition, where the truths defined through the sciences of the last enlightenment (modernity) are not the only undisputed ones. In such an environment, the most proactive socially oriented governments open up the negotiation to a wider public.

The idea of broader public participation is not a novelty of the contemporary urban planning process. In favour of civic practices in the West, it is worth mentioning a brief moment in history when something similar had been attempted in the newly developing cities in the United 
States of America at the end of the $19^{\text {th }}$ century. John Dewey (1927) was a strong supporter of the right to the city, understood as civic and political participation. The concept of civic clubs was developed during the Progressive Era (from the end of the 1890s to the 1920s) in order to put "pressure on the state and other institutions [to create] democracy from below" (Amin \& Thrift, 2002: 133). These clubs were supposed to foster public deliberation, conversation, and education and thus to become models for politically engaged and productive citizens. However, the bottom-up organization of civic societies quickly gave way to a representative system and the "professionalization" of civic rights. In addition, the interest in politics was substituted with a much more "rewarding" yet complacent consumerism (Amin \& Thrift, 2002: 134).

Currently the participation of the public is policy-regulated by the planning practices of EU countries. Public participation is mandatory on the level of the EU, as instructed by the Environmental Impact Assessment (EIA) directive (85/337/EEC) as well as the Aarhus Convention on "Access to Information, Public Participation in Decision-Making and Access to Justice in Environmental Matters". Amongst other things, the convention specifically defines public participation as mandatory "during the preparation of executive regulations and/or generally applicable legally binding normative instruments" (UNECE, 1998).

In the same manner, for example, German planning and building policies rely heavily on an environmental basis, making it mandatory to have at least two public participation debates: first at the "preparatory land use planning level" (Flächennutzungsplan) and second at the "binding land use planning" (Bebauungsplan). These are "early public participation" and "formal public participation", respectfully, mandatory and rigorously regulated by the National Building Code (Pahl-Weber et al., 2008). In addition to these, there is a standing practice of informal planning instruments: from masterplans to participatory workshops (Beckmann \& Wiegandt, 2000). The practice in Slovenia is similar.

However, as the methods, approaches, rules of engagement and level of public engagement are not defined by EU conventions, the participation practices are very diverse. They can turn into an administrative exercise to facilitate the letter of the law rather than its spirit. Here the German best practice should serve as an example. One of the more recent confirmations of the ethical dimension in German planning practice was the non-binding "Tempelhofer Feld Referendum" in Berlin, where $64 \%$ of participants voted against the new developments. The result, in connection with the other public pressures, made the local administration decide to hold off on the private development due to strong public opposition (Hilbrandt, 2017). Even though Hilbrandt is critical of the aims and motivations behind public participation, it is evident that due to a long tradition of public participation and strong civic communities, such as the "100\% Tempelhofer Feld" (www.thf100.de), public participation is planned for and considered seriously by the municipalities and districts.

Public participation efforts and the inclusion of stakeholders have become a significant part of municipality politics and urban planning, not just in theory but also in actual engagement. This is corroborated by a large consultancy market for mediation in the form of agencies dealing specifically with public engagement, such as Zebralog GmbH \& Co KG (Internet 3), IFOK $\mathrm{GmbH}$ (Internet 4) or Polidia GmbH (Internet 5). Whether these serve the administration in order to satisfy the legal requirements or whether they actually serve the public interest is a topic for a separate discussion. These examples show an emerging city administration practice, designed to both facilitate stakeholder engagement and manage public participation in order to reconcile urban conflicts. 
With these two issues in mind, the increasing digitization and complexification of urban governance, due to ever-larger volumes of spatial data on one side and the growing demand for public participation in the planning process on the other, we set up the following two questions in order to test how two suggested interactive tangible PSSs help with the two problems:

- Do the interactive PSSs offer easier access to professional spatial information to nonprofessionals?

- What is the functionality that interactive tangible PSSs contribute to public participation?

\section{Methodology}

We use a comparative method, an approach widely practiced in the humanities as well as the social sciences. First, we describe each technology separately, and, secondly, in the discussion section, we bring together their identified features to reveal the positive and negative sides of each. On the basis of this description, we then, thirdly, conclude by answering the questions set out in the introduction.

The article employs a humanities approach rather than a quantitative social sciences one. This means performing a narrative comparison, where we do not raise all of urban life to the level of quantification and abstraction but instead examine examples concretely-descriptively. In this way, the two posed questions are addressed. Two research-by-practice examples are descriptively compared, where "human understanding arises from a process of inquiry that involves creative action and critical reflection" (Sullivan, 2009: 51). This is similar to the anthropological research method of "thick description" as defined by Geertz (1973), where through a narrative description of a situation the meaning of the situation is qualified even for those who do not understand its cultural context.

The present paper descriptively compares two interactive tangible PSSs, based upon the author's personal experience in developing the Technical University Berlin's Digital Scenario Game and the journal papers and online accounts released by the authors of the MIT CityScope tool and its use at the HafenCity University (HCU). When appropriate, the paper refers to the existing academic literature, mainly in the form of review articles and theoretical and philosophical texts where more fundamental topics are concerned.

\section{Description of the two tangible PSSs}

GISs are specialized tools and are therefore technically complex, requiring specialist knowledge in order to produce results. O'Brien and Cheshire argue that "the creation of maps from demographic data sets was undertaken by geographic information systems (GIS) specialists who had access to complex software packages" (2016: 676). A new generation of online GIS platforms, such as the DataShine project visualising the UK 2011 census information (Internet 6), is making GIS data readily available for viewing to non-professionals. It enables a lay public "without previous GIS training to produce detailed maps from a huge number of data sets" (ibid.). However, the data are not open to manipulation or used as part of an interactive digital tool where users can manipulate the digital information freely and on the spot. Furthermore, regarding Campagna and Deplano's (2004) argument on the non-flexibility of GISs for decision-makers discussed earlier, we can add that in terms of the effort needed to 
carry out professional analysis and simulation, the classical GIS will never be used where "on the fly" decisions, that need instantaneous feedback and information, are being made. "On the fly" decisions refer to the kind of work that is carried out daily by decision-makers, developers and managers or in public participation workshops. For these users and urban stakeholders, a classical visualization of data from GIS information systems is a very limited use of digital technologies. There is ample room to expand the use of computers and GIS tools (Pipan, 2005).

The fast pace of development and an increased amount of spatial information coming from various sources (professional GIS datasets as well as social media sources like Facebook and harnessing smartphone usage statistics like the Google Traffic function in Google Maps) requires a new generation of digital tools that are tailor-made for stakeholder participation in the urban development sphere. In recent years, IT companies as well as university departments, concerned with planning, spatial informatics and design, have initiated "city labs" in order to develop interactive tangible PSSs - fast and responsive tools that enable the kind of strategic decision-making that employs real-time data. The aim of these tools is to be interactive through tangible objects to make spatial information more accessible to various professions and publics.

The present paper will discuss two such interactive examples. The first is the Digital Scenario Game, developed at the Chair for Sustainable Planning and Urban Design, Technical University Berlin, as part of the Modelling City Systems (MCS), Climate KIC research. The second example is the CityScope interactive tool, developed by the Changing Places group at the Massachusetts Institute of Technology.

\subsection{Digital Scenario Game}

Digital Scenario Game is based on the methodology of Scenario Games. ${ }^{1}$ The theoretical source here is provided by Urban Flotsam (Bunschoten et al., 2001) which defines the urban practice "in collaboration with other practices, inhabitants, users, clients, decision makers, producers and investors." According to this text, it is role of "Urban Curators" to "orchestrate this shift in practice, detect emergent phenomena, designate cities as metaspaces, form galleries, and curate their contents" (Bunschoten et al., 2001: 447). Corner comments on the approach as a "projection of 'game-board' structures. These are conceived as shared working surfaces upon which various competing constituencies are invited to meet to work out differences" (Corner, 2011: 239).

\footnotetext{
${ }^{1}$ Scenario Games is a practical implementation of urban gallery methodology (Bunschoten et al., 2001). The following description is based on the document "Urban Gallery Reader", authored by Tomaž Pipan as part of the $\mathrm{PhD}$ research at the London Metropolitan University, partly funded by the Slovenian Human Resources Development and Scholarship Fund.
} 


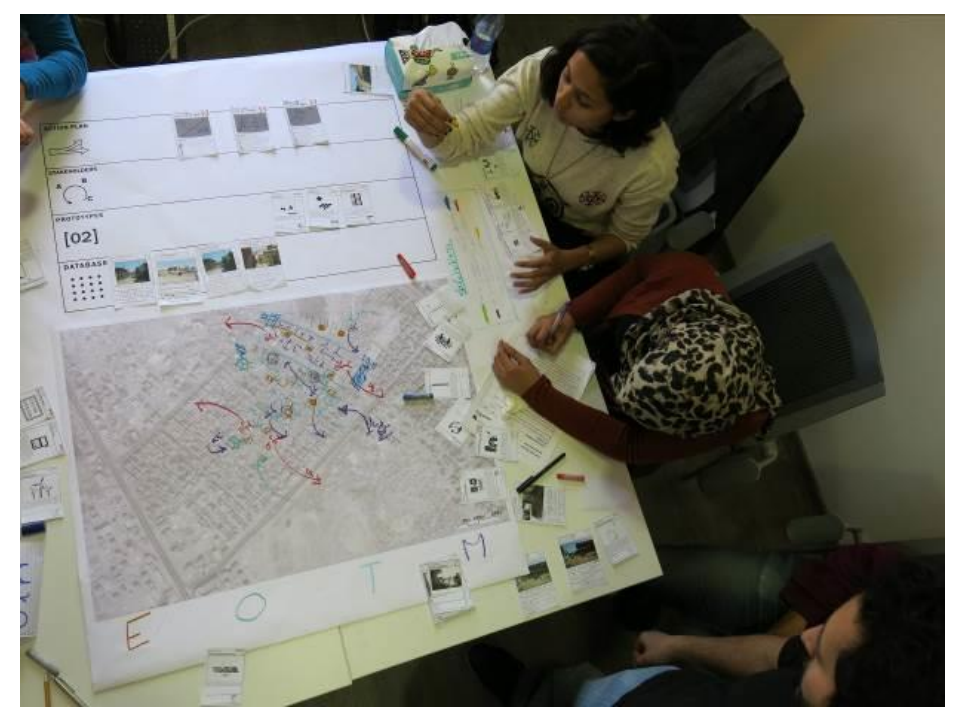

Figure 2: Students playing a classical (analogue) Scenario Game. A negotiation workshop at the El Gouna TU Berlin Campus, Egypt, 2014 (photo: Tomaž Pipan).

An "analogue" Scenario Game creates an environment where different claims on the territory can be confronted and reconciled. "A game reflects reality in that it models its conflicts, but also its dynamics and its ability to construct and develop strategies and pursue them" (Bunschoten 2018). It is a classic example of design thinking methodology working with openended questions implemented in the urban planning environment to settle claims on a territory and adapt them to function together. Scenario Games are played with playing cards on a playing board. The playing cards hold spatial or stakeholder information, problems and opportunities. These can be used for a discussion of the issues at hand which can then be drawn on a map with crayons. The playing board is an actual location, an urban territory (Figure 2). As Corner sums it up, "the graphic map provides the game-board for playing out a range of urban futures. Identified players and actors are brought together to try to work out complex urban issues within an open-ended generative structure" (Corner, 2011: 243).

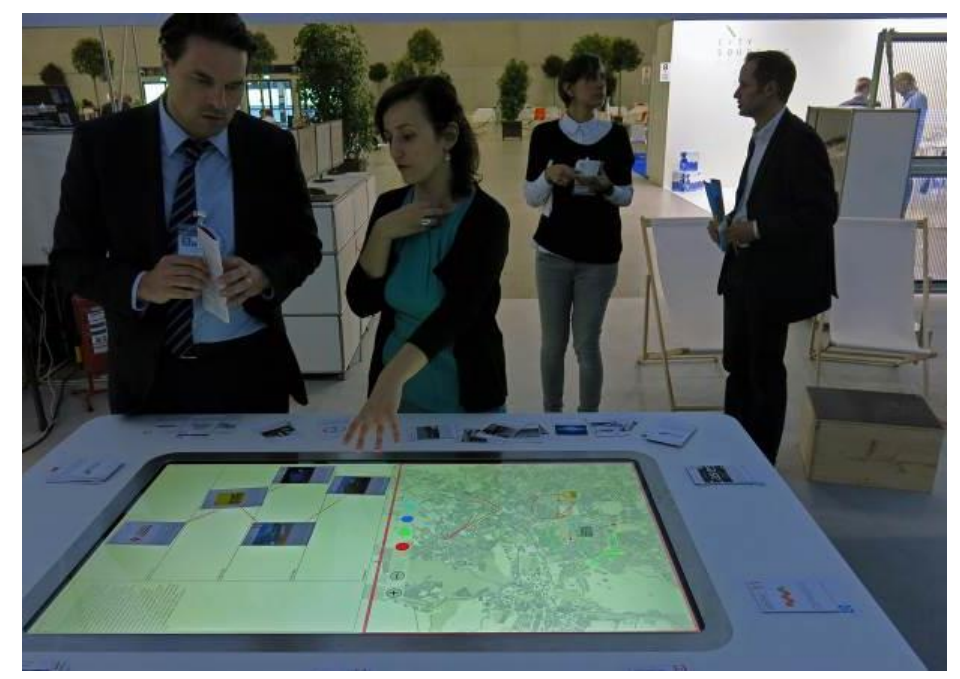

Figure 3: An example of Digital Scenario Game with drawing capabilities where cards trigger spatial information to discuss possible scenarios. (photo: Tomaž Pipan) 
Digital Scenario Game ${ }^{2}$ is a translation and an upgrade of the described concept. It uses industry standard interactive digital table and computers (Figure 3). The playful moment of the classical Scenario Game is maintained by retaining the playing cards and equipping them with QR codes through which the cards are dynamically linked to a digital database. The placement of cards onto the interactive table at the time of negotiation dynamically triggers and displays digital content, from images and maps to movies, graphs, and GIS information (through WMS service). The information needs to be prepared beforehand by the participants through the online web service. Digital Scenario Game can be expanded with additional projections to dynamically show varied information (triggered by the cards) at the time of negotiation on different outputs such as screens, wall projections and the like.

Digital Scenario Game is a real-time dynamic scenario tool that enables different stakeholders to co-develop scenarios for a particular area in real time. The scenarios are developed by direct visual interaction between the stakeholders and a spatial information database. By placing cards on the interactive table, GIS and other information are displayed dynamically, to which the participants can react by drawing and thereby conducting a structured discussion (Gauglitz, 2015). The final product of this negotiation is a Scenario Game Report - a step-by-step record of the process with final conclusions and suggested actions (Figure 4). By comparing different scenarios, the stakeholders can decide which scenario(s) should be retained, changed or further explored.

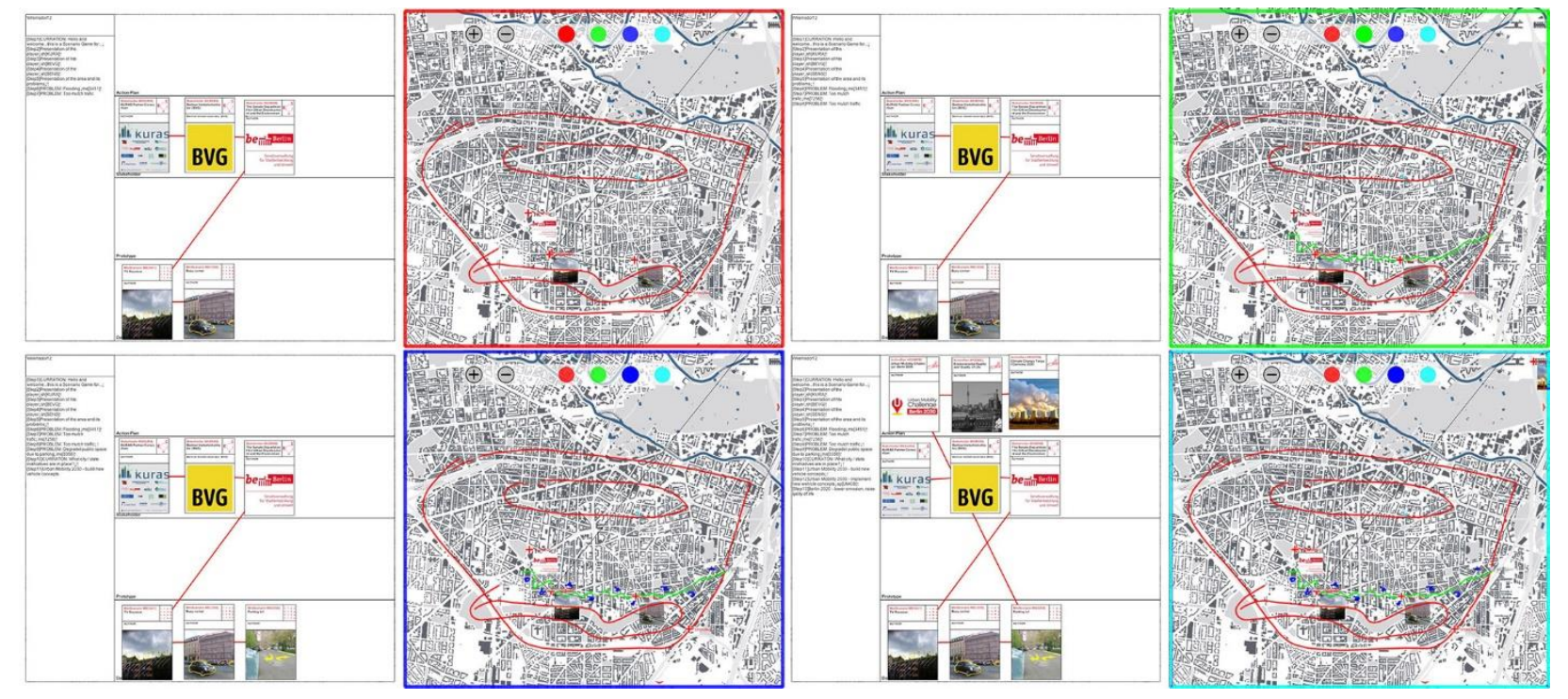

Figure 4: A sequence of print screens (simulation) - a product of negotiation in the Digital Scenario Game. The sequences form a basis for final reporting (illustration: Tomaž Pipan).

The Digital Scenario Game proof of concept was first showcased at the 2015 Metropolitan Solutions fair in Berlin as part of the "TU Berlin BrainBox: Smart City Berlin 2030" exhibition (Ledwig \& Asualyuk, 2015: 76). Under the direction of the present author and with the help of TU Berlin students, we additionally developed a simulation of a negotiation to test the functionality and capability of the Digital Scenario Game at the "Lange Nacht der Wissenschaften 2015" exhibition in Berlin (Gauglitz, 2015). A later version without the recording functions and with a detailed, on-screen presentation of local GIS information was

\footnotetext{
2 The Digital Scenario Game is one part of a larger concept developed at the Technical University Berlin, called the Conscious-City-Lab, formerly BrainBox (Internet 7).
} 
used in Utrecht as part of the Smart Sustainable District (SSD) Climate KIC project (USIUrban, 2016).

\subsection{CityScope}

CityScope technology was developed by the Changing Places group of the MIT Media Lab. The initial technology disclosure paper is titled "System for Real-time Digital Reconstruction and 3D Projection-Mapping of Arbitrarily Many Tagged Physical Objects" (Winder, 2015). "CityScope is an integrated hardware and software platform that merges parametric, voxelized simulations with user-friendly interactive tangible interfaces" (Winder, 2014). It uses an interactive tangible Lego-based interface to create scenarios of urban development based on predefined algorithms, using GIS information for the calculation of new spatial information in real time. By placing the Lego bricks, which act as parameters, the algorithms recalculate the spatial information and show the new results as maps (Figure 5). Noyman et al. (2017: 2465) tie the CityScope technology to a long tradition of research into the interactive tangiblecomputational platforms at MIT; however, CityScope was built specifically to make "complex urban questions accessible and tangible to various audiences".

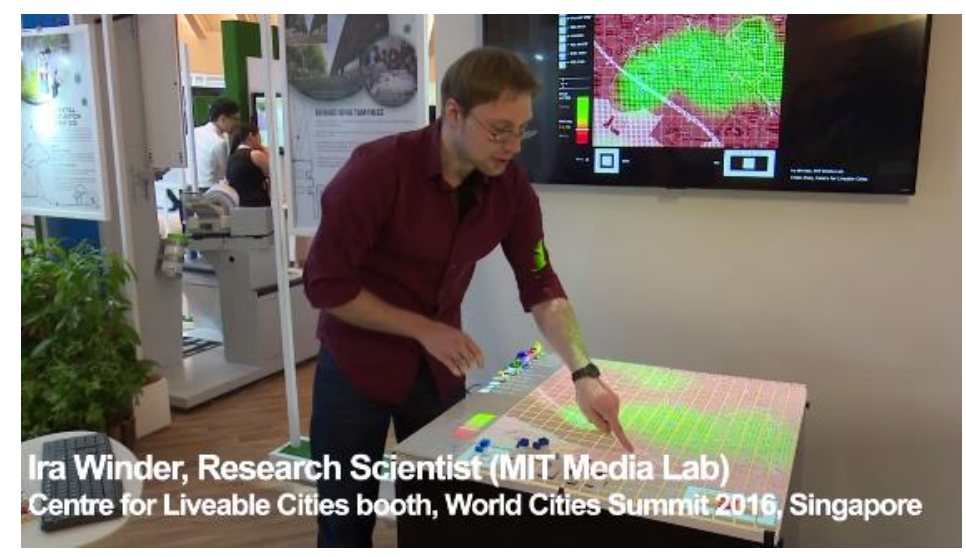

Figure 5: CityScope technology presented by Ira Winder on the walkability example (source: CentreforLiveableCities, 2016).

The system is a combination of technologies: 3D-tagged objects (Lego bricks), projector, computer, sensor, and display (Winder, 2015). It encompasses many different software module functionalities, from using the tactile interface of Lego bricks as buttons and switches to using them as tagged elements in a scenario. A highly didactic example is a walkability simulation (Figure 5) presented in the product video for the World City Summit 2016 in Singapore in collaboration with the Centre for Liveable Cities and Urban Redevelopment Authority Singapore (CentreforLiveableCities, 2016).

CityScope as a commercial service needs additional bespoke programming to solve a specific task. It requires preparation of spatial information and integration with specific algorithms that calculate a spatial solution. For example, CityScope can be made to solve a question of walkability in an area where walkability is presented as a "function of the amenity and their placement" (CentreforLiveableCities, 2016). By placing new amenities, such as shopping areas or hospitals, walkability increases. By placing different type of amenities in different locations, scenarios of different walkability capacities can be compared and the most optimal one chosen. In other words, by direct tangible interaction with the Lego blocks, users can change scenarios of development in real time. Through algorithms, actions change spatial data and trigger 
instantaneous recalculations of values, which are then projected as results back to users. This feedback of action can be a calculated result in the form of the influences, impacts and performance of the current urban setup.

CityScope has been tested and commercially implemented in numerous situations. The HCU CityScienceLab in collaboration with city of Hamburg has implemented a series of stakeholder engagement workshops (Internet 8) where the CityScope technology is used in public workshops as a tool to dissipate tensions, connected to the topic of refugee accommodation: "The goal was to incorporate the citizens' personal experience and local knowledge into the political and administrative evaluation of potential locations" (Noyman et al., 2017: 2465). Between May and July 2016, the HCU held 34 two-hour workshops for the seven districts of Hamburg with a total of 400 participants. With the help of CityScope technology, the participants were able to identify 44 prospective sites for accommodation out of the initial 161 (Noyman et al., 2017: 2469-70). The participatory framework enabled the stakeholders to dynamically act upon GIS data, such as plot programs and ownership, as well as act upon their own understanding and local experiences. As reported by the team, the citizens "felt as partners in an 'eye-level' dialogue with [the] policy makers and city administration" (Noyman et al., 2017: 2471).

\section{Discussion}

When it comes to the two questions posed regarding the interactive tangible PSSs, four main topics were identified, which will be discussed here. In terms of access to professional spatial information for non-professionals, (1) tangible interface and physical setup, and (2) data provision and workshop accessibility are discussed. In terms of PPSs' role in augmenting public participation, (3) augmenting the public knowledge and (4) unique functionality are addressed.

\subsection{Tangible interface and physical setup}

The tangible interface (playing cards in the Digital Scenario Game and Lego bricks in CityScope) creates easier access to professional information. Instinctive physical gestures are used to trigger complex functions or reveal spatial information that would otherwise require computer peripherals. However, one technical limitation of both systems is the size of the technology. When facilitating public participation, it is important to accommodate the workshops locally, in a public hall or administrative office. This means moving the setup around to different places. Due to the tangible functionality, both technologies are large physical setups. The industry standard interactive table used in the Digital Scenario Game is approximately $1.6 \mathrm{~m} \times 1 \mathrm{~m}$ in size. The interactive tables at the HCU are bespoke tables $2 \mathrm{~m} \times$ $2 \mathrm{~m}$ large. Combined with the need for a good Internet connection, dedicated computers, screens and projections, these are physical and technical limitations that require significant time and effort for transport and setup. The FindingPlaces workshops in Hamburg using the CityScope technology solved the problem by hosting all workshops at the HCU in the CityScienceLab, which the participants found inconvenient (Noyman et al., 2017: 2471). Public participation can be very sensitive, and such reasons can affect the number of participants and their mood, biases and willingness to give relevant feedback. The same problem was faced by the Digital Scenario Game technology when a workshop required its transportation. Due to all the complications, we decided to do a classical "analogue" scenario game without the digital table. 


\subsection{Data provision and workshop outreach}

The preparation of the data for the Digital Scenario Game can be done by all the participants prior to or during the workshop. Through an online interface, participants can upload images, texts, locations, problems and ideas. This contributes to a more informed participation environment and ensures better participant turnout. When it comes to professional information, GIS data can be uploaded via a web map service, for which GIS knowledge is already required. Integration of existing GIS databases is also possible but requires geoinformatics and programming skills, usually supplied by the developers. Similar limitations are observed with the CityScope technology. As it works on the basis of GIS information, the data have to be properly formatted and connected to the interactive environment. For special types of interactions (like the HCU FindingPlaces workshops), bespoke algorithms have to be created (Noyman et al., 2017: 2468-9).

In terms of workshop outreach, the specificity of such intense participatory workshop formats is that the participation is considered successful when the number of participants per curator falls within a certain boundary. Only then can the decision-making process be well-informed. This largely depends on the method of the design thinking process applied. For the Digital Scenario Game, this is on the order of four to eight people per curator. Larger groups do not achieve the desired effect due to constant deliberations instead of a proactive solving of the problems. In the case of FindingPlaces, the workshops accommodated at most 20 people per session (Noyman et al., 2017: 2469). To accommodate a larger number of participants, the workshop group would need to be multiplied. This also means multiplying the number of interactive tools per individual workshop, a limitation for formats where public opinion needs to be gathered on a massive scale. For such formats, companies like Zebralog use proprietary online solutions. For example, the "Dialogzentrale, the 'mother of all dialogues', offers a platform with participation infrastructure and various modules" (Internet 9).

\subsection{Types of participation augmentation}

The two examples described above show two different approaches to using digital interactive technology in terms of augmenting public participation. We could classify them as passive and active planning support augmentations.

The Digital Scenario Game is of the passive kind. It is a solution that uses digital technology in order to represent the gathered information in a faster, more convenient and dynamic way, giving access to spatial data "on the fly". In addition, it can record the process of negotiation to review and improve the scenarios. It does not create additional spatial data: all of the creation and speculation is done based on the participants' knowledge and experience. In this sense, it is also a tool for capturing professional knowledge on one side and public opinion and suggestions on the other. This augmentation significantly enhances participation because it automates certain parts of negotiation and makes it run more smoothly.

The CityScope technology is an active kind, with simulation capabilities based on preimplemented algorithms that generate new spatial data in real time. The algorithms extrapolate the most likely solution and offer it as a given to the users of the negotiation process. The CityScope technology actively changes the negotiation process by suggesting simulated results. The results in turn largely depend on the analytical expertise and technical skills of the 
programmers. This is a very advanced type of participation augmentation and a unique functionality, whose problems and limitations are addressed below and in the conclusion.

\subsection{Unique functionality}

The passive Digital Scenario Game is able to present spatial information in a more convenient way than classic GIS can; however, it cannot offer a synthesis. The interpretation of spatial data, from understanding the maps to reading the graphs, is still largely dependent upon the participants' skill and experience, which suggests that the reaction of the lay public might be limited. It is, however, a good tool to trace and record public "mood", bring experts and the local public together, and gather local spatial information that otherwise might not be available to the professionals..

The active CityScope offers synthesis and interpretation of spatial information in the form of speculated simulated results, such as the dynamically changing walkability maps that respond to users' interactions. This means that the lay public can act on information that is more complex and devise a solution which is a product of the professional knowledge imbedded in the algorithms. However, one of the more serious limitations we have to consider is the method through which the simulated spatial information is produced. Just as the lay public is perhaps unable to mentally work out and project the walkability, it is equally difficult to understand the simulated result in its entirety. This must be taken into account when using and interpreting such participatory results.

\section{Conclusion}

The paper discusses two examples of interactive tangible PSSs to illuminate how PSSs increase the usability of professional spatial information on one hand and how they contribute to consensus-making on the other. It investigates the ways in which to bring different stakeholders together in a structured way to manage the process of urbanization and to ensure better usability of digital spatial information in the participatory planning process, specifically:

1. Do the interactive PSSs offer easier access to professional spatial information to nonprofessionals?

In terms of "tangible interface and physical setup" (see 4.1), the tangible aspect helps with the access to the information; however, the physical size and difficulties with the transportation of interactive PSSs are a big hindrance to scaling the services. This also presents a limitation to the inclusion of a wider public in the negotiation process, subsequently lowering the access to spatial information for non-professionals. We considered turning the Digital Scenario Game into an online solution (SaaS), thus losing the tactile moment of physical cards. This would make it more portable; however, the tactile moment is very important to design thinking methods for public participation as it gives people control and authority. We have to conclude that size and technical complexity are limitations of the interactive tactile PSSs that will be hard to overcome. If the tactile moment makes access to the professional spatial information easier for participants, it is the physical setup that limits the scalability and wider public outreach of such systems.

In terms of "data preparation and workshop outreach" (see 4.2), we can conclude that the preparation of information by users for the Digital Scenario Game is fairly easy when considering uploading information prior to the workshop. However, the main hurdle of having 
to prepare the GIS information by GIS experts and make it product-ready remains unresolved. CityScope's problems are even more pronounced as it cannot be used without the serious preparation of information for every specific problem. In terms of workshop outreach, the workshops can accommodate only a rather small number of stakeholders. This is a serious hindrance, especially when it is important to gather a huge amount of information. In this regard, online digital participation solutions offered by existing participation providers such as Zebralog, IFOK or Polidia make more sense. This also shows an inherent limitation of interactive digital tools for public participation. Online digital tools can cover relatively large public samples, which in turn limits the capacity of individuals to significantly contribute to urban decisions. On the other hand, the interactive tangible PSSs can cover a focus group that can make concrete suggestions but might not be representative of a larger public sample.

2. What is the functionality that interactive tangible PSSs contribute to public participation? In reference to "unique functionality" (see 4.4), both technologies show significant promise when it comes to raising the quality of public participation.

Digital Scenario Game enables the participants to adduce and refer to classical spatial information in real time during the process of negotiation-something that the classical GIS solutions cannot. It can be seen as the next step to online user-friendly GIS services such as DataShine. The capacity to show dynamically different spatial information and other visual information helps curators of the scenario to better inform the participants and to achieve a better output. On the other hand, the limitation — as well as the advantage — of such solution is that the technology represents only the spatial information and makes no judgment upon it.

The CityScope technology enables decision-making and negotiation on the basis of synthesis and spatial information generated in real time. This allows the lay public to make decisions on the basis of the expert knowledge imbedded in the algorithms. CityScope can be understood as a next-generation digital support tool that actively engages in the participation process. However, this does not make moot the point of required spatial literacy, such as understanding geographic maps. It was reported that the "non-expert participants had trouble understanding the professional planning content" (Noyman et al., 2017: 2471).

In reference to the "types of participation augmentation" (see 4.3) in the active CityScope example, we have to consider that the public's decisions are dependent upon the results generated by an algorithm whose logic is dependent upon the programmer. If instead the algorithm was replaced by a dynamic process curated and moderated by an expert (for example, an urban planner explaining, commenting and showing possibilities for better walkability), the participants' decisions might be different. The simulated solutions presented by the computer are rendered as undisputed truths with a single presentation of a solution, circumventing Latour's "matters of concern" and painting them as "matters of fact".

The matter-of-fact character of results generated by digital technologies is useful for planning administrations as it gives concrete answers where otherwise there are none. The solutions miraculously appear and are taken as "scientific fact", releasing individuals (city officials and scientists alike) from responsibility on one hand and making the process seem objective, transparent and convincing on the other. This needs to be taken into account when analysing and using results of such type. Noyman et al. also cautions that "the approach runs danger of becoming instrumentalized by political forces or interest groups" (2017: 2472). This suggests that it is of paramount importance to put in charge of such negotiations a professional who can interpret both the data and visual results as well as the stakeholders' input. The idea of a new 
profession, a curator-designer, is emerging as a new type of expertise that would also need fostering in architectural and planning schools (Pipan, 2014: 162).

In conclusion, we need to consider the popular belief that general public participation brings about wider public acceptance and better public consensus. Hillier (2003) traces the deeply rooted cultural belief that consensus is synonymous with good social ethics to Habermas's "theory of communicative action", in which "reciprocal understanding" presupposes humans as explicitly rational beings. However, Hillier (2003: 41) argues that "the ideals of communicative rationality and consensus-formation are rarely achieved". In a similar manner, in reference to practical examples, Hilbrandt (2017: 546) clearly points out that "planners willingly admitted that participation was suspended at crucial moments [...] in order to circumvent a broader public debate". This alludes to the fact that public consensus is a cultural bias and a (mis)interpretation of the plural right to the city and is not necessarily achievable. One of the pragmatic reasons we can single out is the sheer number of people living in contemporary cities, rendering direct democracy unfit for consensus. Even Arendt, an avid supporter of the political civic city, acknowledges the problem of size and scope in achieving consensus. We can see the "civic city" being forfeited to the "social city", especially because "the larger the population in any given body politic, the more likely it will be the social rather than the political that constitutes the public realm" (Arendt, 1985: 43).

In final conclusion, it is the opinion of the author that, first, the lay public can take more informed decisions through public participation by having the digital information ready at hand in real time during the participation event. However, whether their suggestions and input meaningfully contribute to the planning process is not dependent upon the sophistication of the digital technologies employed but upon the city administration and the ethics of governance. Secondly, the urban planning solutions that go through the process of public participation with interactive tangible PSSs will benefit from local knowledge that otherwise cannot be obtained. However, it is of paramount importance that the professional - the curator-designer-curates and manages the process. Such a professional has unique knowledge to interpret spatial information on one side and manage the diverse intentions of the participants on the other. This is even more important for the active tangible interactive PSSs like CityScope, where the results generated need context that only a professional can provide. Yet, the need for the reconciliation of large numbers of people and the inherent need for direct democracy in larger cities is a cultural bias, and will thus not be solved through an implementation of new technologies but rather needs an understanding of what public participation means and can achieve in combination with a high level of ethical responsibility that should be fostered within urban culture.

Tomaž Pipan, University of Ljubljana, Biotechnical Faculty, Department of Landscape Architecture, Ljubljana, Slovenia (tomaz.pipan@bf.uni-lj.si)

\section{Acknowledgments}

The Digital Scenario Game PSS was developed at the Chair for Sustainable Planning and Urban Design, Technical University Berlin. It was partly funded by the EIT, Climate KIC, under the Modelling City Systems project. The Digital Scenario Game tool was developed as part of Work Stream II-6: Development of multimedia performance space: BrainBox (later renamed Conscious-City-Lab). Developers of the digital interactive Scenario Game: Lead: Dr. Tomaž Pipan; Holger Prang, Akitoshi Honda, Arne Siebenmorgen, Matthias Lieb, Murad Mulhem, Steven Watson. Project supervisor: prof. Raoul Bunschoten. 


\section{References}

Amin, A. \& Thrift, N. (2002) Cities: reimagining the urban. Cambridge, UK, Polity.

Arendt, H. (1958) The human condition. Chicago, IL, University of Chicago Press.

Beckmann, G. \& Wiegandt, C. C. (eds.) (2000) Stadtentwicklung und Städtebau in Deutschland: ein Überblick. Bonn, BBR.

Bunschoten, R. (2018) From smart city to conscious city. In: Holstenkamp, L. \& Radtke, J. (eds.) Handbuch Energiewende und Partizipation, pp. 769-791. Wiesbaden, Springer Fachmedien Wiesbaden. DOI: 10.1007/978-3-658-09416-4 46

Bunschoten, R., Hoshino, T. \& Binet, H. (2001) Urban flotsam stirring the city: CHORA. Rotterdam, 010 Publishers.

Campagna, M. \& Deplano, G. (2004) Evaluating geographic information provision within public administration websites. Environment and Planning B: Planning and Design, 31, pp. 21-37. DOI: 10.1068/b12966

Caragliu, A., Bo, C. D. \& Nijkamp, P. (2011) Smart cities in Europe. Journal of Urban Technology, 18(2), pp. 65-82. DOI: 10.1080/10630732.2011.601117

CentreforLiveableCities (2016) Demonstration of CLC-MIT's tangible interactive modelling. Available at: https://www.youtube.com/watch?v=5EEyB-rsHew (accessed 4 May 2017).

Corner, J. (2011) The agency of mapping: speculation, critique and invention. In: Dodge, M., Kitchin, R. \& Perkins, C. (eds.) The map reader: Theories of mapping practice and cartographic representation, pp. 89101. Hoboken, NJ, John Wiley \& Sons. DOI: 10.1002/9780470979587.ch12

de Jong, M., Joss, S., Schraven, D., Zhan, C. \& Weijnen, M. (2015) Sustainable-smart-resilient-low-carboneco-knowledge cities; making sense of a multitude of concepts promoting sustainable urbanization. Journal of Cleaner Production, 109, pp. 25-38. DOI: 10.1016/j.jclepro.2015.02.004

Dewey, J. (1927) The public and its problems. London, Allen \& Unwin.

Gauglitz, D. (2015) CHORA Conscious City Lab @ Lange Nacht der Wissenschaften 2015 in Berlin. Available at: https://vimeo.com/137976637 (accessed 23 Jan. 2018).

Geertz, C. (1973) The interpretation of cultures: Selected essays. New York, Basic Books.

Hilbrandt, H. (2017) Insurgent participation: consensus and contestation in planning the redevelopment of BerlinTempelhof airport. Urban Geography, 38(4), pp. 537-556.

Hillier, J. (2003) 'Agon'izing Over Consensus: Why Habermasian Ideals cannot be 'Real'. Planning Theory, 2(1), pp. 37-59. DOI: 10.1177/1473095203002001005

Internet 1: https://www.ibm.com/us-en/marketplace/city-insights (accessed 5 May 2017).

Internet 2: https://blog.nationalgeographic.org/wp-content/uploads/2012/05/May-3-Post-Sala-de-Controle1.jpg, (accessed 19 June 2018).

Internet 3: www.zebralog.de (accessed 19 June 2018).

Internet 4: www.ifok.de (accessed 19 June 2018).

Internet 5: www.polidia.de (Accessed 19 June 2018).

Internet 6: http://datashine.org.uk (Accessed 19 June 2018).

Internet 7: http://www.chora.tu-berlin.de/Conscious-City-Lab/ (accessed 19 June 2018).

Internet 8: https://findingplaces.hamburg/ (accessed 19 June 2018).

Internet 9: https://www.streifentechnik.de/\#about (accessed 30 Jan. 2018).

Kar, B., Sieber, R., Haklay, M. \& Ghose, R. (2016) Public participation GIS and participatory GIS in the era of GeoWeb. The Cartographic Journal, 53(4), pp. 296-299. DOI: 10.1080/00087041.2016.1256963

Kitchin, R. (2016) The ethics of smart cities and urban science. Philosophical Transactions of the Royal Society. A, 374(2083), pp. 1-15

Kohsaka, H. (2000) Applications of GIS to urban planning and management: Problems facing Japanese local governments. GeoJournal, 52(3), pp. 271-280. DOI: 10.1023/A:1014228426254

Latour, B. (2004) Politics of nature: How to bring the sciences into democracy. Cambridege, MA, Harvard University Press.

Ledwig, M. T. \& Asualyuk, A. (eds.) (2015) Metropolitan solutions magazine 2015. Stuttgart, Local global $\mathrm{GmbH}$. Available at: https://issuu.com/localglobal/docs/msm_final_low_1105 (accessed 22 January 2018).

Noyman, A., Holtz, T., Kröger, J., Noenning, J. R. \& Larson, K. (2017) Finding places: HCI platform for public participation in refugees' accommodation process. Procedia Computer Science, 112, pp. 2463-2472. DOI: 10.1016/j.procs.2017.08.180

O'Brien, O. \& Cheshire, J. (2016) Interactive mapping for large, open demographic data sets using familiar geographical features. Journal of Maps, 12(4), pp. 676-683. DOI: 10.1080/17445647.2015.1060183

Pahl-Weber, E. \& Henckel, D. (eds.) (2008) The planning system and planning terms in Germany: A glossary. Available at: http://www.ssoar.info/ssoar/handle/document/28560 (accessed: 1 Jul. 2016).

Pipan, T. (2005) Računalnik kot generativno orodje. Urbani izziv, 16(2), pp. 88-93. 
Pipan, T. (2014) Teaching for urban complexity in smart cities. In: Fikfak, A. \& Mojca, V. (eds.) Smart urbanism: Teaching sustainability, pp. 157-167. Ljubljana, Faculty of Architecture.

Sullivan, G. (2009) Making Space: The purpose and place of practice-led research. In: Smith, H. \& Dean, R. T. (eds.) Practice-led research, research-led practice in the creative arts. Edinburgh, Edinburgh University Press.

UNECE - The United Nations Economic Commission for Europe (1998) Convention on access to information, public participation in decision-making, and access to justice in environmental matters. Aarhus.

USIUrban (2016) SSD Utrecht interaction table. Available at: https://www.youtube.com/watch?v=u30R5F8SDhc (accessed 4 May 2017).

Vonk, G., Geertman, S. \& Schot, P. (2007) A SWOT analysis of planning support systems. Environment and Planning A, 39, pp. 1699-1714. DOI: 10.1068/a38262

Winder, I. (2014) City planning technology invented by MIT - CityScope Mark II. Available at: https://www.youtube.com/watch?v=JEH01UvjzD0 (accessed 4 May 2017).

Winder, I. (2015) System for real-time digital reconstruction and 3D projection-mapping of arbitrarily many tagged physical objects. Provisional Patents. 
